control priorities for potential invasive species could be based on easily available data about natural history and evolutionary ecology. We propose four guidelines for identifying such invasives.

An exotic organism may be more likely to invade and cause disruption the greater its rate of reproduction; the greater its dispersal ability; the closer (phylogenetically) its preferred food in its native range is to an abundant taxon in the new range; and the farther away (phylogenetically) its predators and pathogens are in its native range from those in its new range.

For example, the red turpentine beetle (Dendroctonus valens) is not particularly disruptive in its native range in North America because it attacks only trees that are already weakened. In China it attacks and kills healthy trees (Z. Yan et al. Biodivers. Conserv. 14, 1735-1760; 2005). The reasons for this beetle's success as an invasive include its high dispersal and reproductive rates, its affinity for Chinese pines closely related to those it feeds on 'at home', and the lack of predators or pathogens phylogenetically similar to ones found in North America.

Manuel Lerdau Xishuangbanna Tropical Botanical Garden, Chinese Academy of Sciences, Menglun, Yunnan, China; and University of Virginia, Virginia, USA.

mlerdau@virginia.edu

Jacob D. Wickham Institute of Chemistry, Chinese Academy of Sciences, Beijing, China.

\section{UK cancer genetics gets personal}

There is a promising way in which personalized medicine can be incorporated into healthservice infrastructure (Nature 473, 253-254; 2011). In the United Kingdom, the charity Cancer Research UK is leading a partnership with AstraZeneca, Pfizer and the government's Technology Strategy Board to help the National Health Service to adopt a consistent approach to genetic testing for targeted cancer therapies, and to promote further research into personalized treatment.

The first phase will run from 2011 to 2013 and cost $£ 5.5$ million (US\$8.8 million). The programme will model the processes required for routine testing of tumour molecular characteristics and for secure storage and retrieval of molecular and clinical data for research. It will involve seven Experimental Cancer Medicine Centres and 9,000 patients with one of six tumour types: breast, colorectal, lung, prostate, ovary and metastatic melanoma. Up to 22 mutations will be tested, with the aim of harmonizing practices across the centres and labs.

The second phase will establish a molecular diagnostics service to deliver high-quality, standardized tests for patients nationwide and to obtain routine consent for the collection, storage and research use of data on genetics, treatments and outcomes. The long-term strategy includes the flexibility to accommodate new technologies, other cancer types and other disease areas.

Cancer Research UK is in discussion with similar initiatives in the United States, France, Australia and elsewhere to exchange information on mistakes and successes.

David Wiseman, Alice Tuff, James Peach Cancer Research UK, London, UK.

david.wiseman@cancer.org.uk

\section{Nuclear winter was and is debatable}

Alan Robock's contention that there has been no real scientific debate about the 'nuclear winter' concept is itself debatable

(Nature 473, 275-276; 2011).

This potential climate disaster, popularized in Science in 1983, rested on the output of a onedimensional model that was later shown to overestimate the smoke a nuclear holocaust might engender. More refined estimates, combined with advanced three-dimensional models (see go.nature.com/ kss8te), have dramatically reduced the extent and severity of the projected cooling.

Despite this, Carl Sagan,

who co-authored the 1983

Science paper, went so far as to posit "the extinction of Homo sapiens" (C. Sagan Foreign Affairs 63, 75-77; 1984). Some regarded this apocalyptic prediction as an exercise in mythology. George Rathjens of the Massachusetts Institute of Technology protested: "Nuclear winter is the worst example of the misrepresentation of science to the public in my memory," (see go.nature.com/yujz84) and climatologist Kerry Emanuel observed that the subject had "become notorious for its lack of scientific integrity" (Nature 319, 259; 1986).

Robock's single-digit fall in temperature is at odds with the subzero (about $-25^{\circ} \mathrm{C}$ ) continental cooling originally projected for a wide spectrum of nuclear wars. Whereas Sagan predicted darkness at noon from a US-Soviet nuclear conflict, Robock projects global sunlight that is several orders of magnitude brighter for a Pakistan-India conflict literally the difference between night and day. Since 1983, the projected worst-case cooling has fallen from a Siberian deep freeze spanning 11,000 degreedays Celsius (a measure of the severity of winters) to numbers so unseasonably small as to call the very term 'nuclear winter' into question.

Russell Seitz Massachusetts, USA.

seitz@physics.harvard.edu

\section{All-male line-up yet again}

Most prestigious prizes in science that are not set aside for women go primarily or only to men. The eight male 2010 Kavli prizewinners in astrophysics, nanoscience and neuroscience are the most recent examples (see go.nature.com/5xh17n).

The Kavli winners are accomplished and deserve their honours. But the frequency of all-male line-ups, and the number of meritorious women, indicates that women as a group are disproportionately overlooked. Why?

Gender schemas -

cognitive structures that summarize our beliefs about the sexes - portray women primarily as nurturing and communal, and men as capable of independent action and work-oriented (V. Valian Why So Slow? The Advancement of Women; MIT Press, 1998). Such schemas mean that women's names are unlikely to come to nominators' minds; if women are considered, they are less likely than men to be perceived as prizeworthy (see also Nature 469, 472; 2011).

Prizes matter in part because young women with scientific abilities and interests are more likely to aim high if they see examples of women receiving top awards. Why stay in a field where you have little chance of recognition? We are squandering the abilities of half the human race.

Prize committees need to learn where, how and why our perceptions give men an edge. Committees also need actively to solicit nominations of women and members of under-represented groups. Few guidelines, including those for the Kavli prize, include such encouragements. It is time to stop this cycle of neglect of outstanding women in science. Virginia Valian Hunter College and CUNY Graduate Center, New York, USA.

virginia.valian@hunter.cuny.edu

\section{CORRECTIONS}

An editing change ( $T$. Leitner et al. Nature 473, 284;

2011) confused the point that phylogenetic experts should formulate an a priori hypothesis based on HIV epidemiological information.

B. Bosquet (Nature 474, 36; 2011) notes that Cameroon's REDD Project Idea Note was prepared with the WWF's full support. Nature's headline was not intended to undermine efforts by governmental and non-governmental organizations. 